\title{
THE DYNAMICAL ASPECT OF THE VISUAL COMMUNICATION: THE SYSTEM COMPREHENSION
}

\author{
Nataliia Skliarenko ${ }^{1}$ \\ Marina Kolosnichenko²
}

DOI: https://doi.org/10.30525/978-9934-26-050-6-68

Visual communications create the harmonious environment and make it possible for people to adapt to its continuous changes. At the same time constant visual communications (e.g. advertising, navigation aids, additional information media, etc.) should also continuously change to suit the modern reality. That's why designers should constantly search for new methods of the designing to achieve more effective interaction with the consumer.

We consider visual communications simultaneously as the process of the imaging and transmission the information by using the means of the visual language and visual imaginative perception that certainly have powerful emotional coloring. In that case, dynamics provide the formation of the multipurpose area for communication and show the importance of the design characteristic. Dynamic images cause the increasing of the number of the visual contexts. The experimental nature of the visual communications makes the designing of dynamic images more complex. It is important to predict the results of the perception. That's why the theoretical comprehension of the dynamical aspects in the visual communications based on the system approach is the most promising way of the development.

A lot of the researches of visual communications attention are connected with the correlation of the concepts of the graphic design and the design of

\footnotetext{
${ }^{1}$ Kyiv National University of Technologies and Design, Ukraine

${ }^{2}$ Kyiv National University of Technologies and Design, Ukraine
} 
visual communications [2, p. 4], the analysis of communications in the context of the design and the problems of the strategy and methodology of the communication design [1]. It is necessary to understand the differences between various kinds of communication and learn more various ways of the consumers' reaction [4]. So, we investigate visual communications on the theoretical and practical levels.

The movement, which is an important part of the project activity, appears through the creation of the real or the imitative dynamic in design [3, p. 59-60]. The purpose of the project is the increase of the dynamism of the visual communications at the expense of integration with a human, and with natural and artificial environment. It causes the importance of the detection of different kinds of the dynamical changes while using the systemic approach.

While we use the wide variety of the artistic innovations, scientific, technical and digital technologies, we develop and complicate the visual communication and make it more dynamical. Visual communication is not only static object, but a process as well. So, the design system is able to continuously change. It leads to the increase of the quality of the perception and the memorization of the visual message. In order to further form the theoretic base and practice of the visual communication designing system we need to analyze the types of the dynamical processes.

The process represents the repeated or not repeated sequence of actions that expresses the idea. The course of the processes is provided by the internal means of the design system that arises during the motion of the human. The project method of creating the new object or phenomenon is the dynamic formation in this case. We emphasize different kinds of processes depending on the character and the features of the structural elements of the design system.

Mechanical processes represent repetitive in time periodical actions of the constructive elements of the carrier of the visual image. Such processes are typical for the external advertising or transport advertising (the opening/closing of the doors, the movement of the janitors, wheels, etc.). They can be posted on the small architectural forms, in elevators as the internal advertising, on escalators and other movable objects. Sound, light and other kinds of information are ancillary in this case. However, this information plays an important role in the designing of the figurative solution. The visualization of the repetitive mechanical processes is perceived as the system of the dynamical composite elements of different levels. They are agreed conceptually and combined with the communicative connections.

The complication of the visual communication language occurs due to the inclusion of electronic and digital technologies into design system (e.g. the eye tracking, motion tracking, temperature tracking, the measuring of the 
weight, etc.). The informational-technical processes visualize the life stories as the single complex of the transformation of the objects or events. Due to the consistent transformation hidden qualities and the information appear. They are not on the surface, but they cause the appearance of the new functions. That's why multifunctionality is the specific feature of the dynamical visual communications. It makes them a useful instrument in the life of the society.

The dynamical visual number is formed with the using of the digital technologies and the augmented reality technologies. It is adapted in real time to the weather conditions, the people's behavior and different movements. This visual row is synchronized with the environment and the person's actions. The active implementation of the modern informational and communicative technologies into the social reality contributes the maximum involvement of the communications users and makes the visual communications intuitive and clear for others.

The biochemical processes make the internal dynamical changes of the visual images. Their visualization represents the totality of the objects conditions, which are caused by the chemical changes on the molecular level and are irreversible in time. The means of the dynamic visualization is the color.

One of the promising ways of the visual communication designing is the ability to visualize the temperature regimes, the expiration date of the products, and regime of the storage at the expense of the development of the appropriate indicators (e.g. «Bad Meat Detector», To-Genkyo-Tokyo, 2009). The colorful dynamic informs about the changes that are hidden in the processes.

Using the biochemical changes has the system character and provides the involvement into the designing of the dynamical visual communications of a board of the professionals (e.g. the alive bacterium billboard «Contagion», Toronto, Canada, 2011). Using of the behavior and features of the living creatures (bacterium, insects, and animals) for the modeling of the visual communications can become one of the main directions in solving the ecological problems.

The appearance of the real people on the advertisements describes the specific of the using of the antroposocial processes, which cause the intensive communication (billboards with real people). The high level of the dynamics characterizes the design systems, where the process visualization happens with the environment (pet shop JAKPETZ JAKARTA, Indonesia, 2009; customers are fleas on the dog here). Dynamical visual image becomes the area for the multilevel communication. It represents different fragments of the information for the observer and the member of the design system. 
We consider communications based on the antroposocial processes as the way of the life and they often are used with the purpose of the interactive study (e.g. research of human growth «World Dimension», Slovak). Therefore we observe the formation of the specific visual communicative space, which gradually transform. Dynamical visual communications become the integrated fragment of the social and cultural reality.

The involvement of the natural processes into the visual communications composition provides the formation of the systemic dynamic communication. Periodic changes of the conditions of the natural environment (natural phenomena and climate parameters) create the ability for the constantly updated communication with the viewer and effective usage of the natural resource potential. The mechanism of the adaptation to the action of the factors of the environment becomes the main in the creating of the image solution.

The totality of the influences of the artificial environment (dust, dirt, artificial light, warmth, etc.) emphasizes the close interactions between processes and phenomena and makes it possible to rethink the role of the informational message and is considered as the way of increase of the ecoconsciousness (e.g. the cleaning company advertising «Clean Plus», Thailand, 2013). The dynamic designing acquires the ecological direction, provides the complex comprehension of the reality and creates the visual integrity, which has integral properties.

Real dynamical processes are dominant in the designing of visual communications. On the other hand, illusory images play an important role. The mental perception of the reality provides the modifications of the science paradigm of the visualization based on the imitation of the processes. The moving of the viewer in the space along the design system, which is divided into the fragments, ensures the illusion of the movement, changes of its states of forms. One more kind of the illusory dynamical formation is mirror symmetry (the addition of the half of the real object at the expense of the reflection of the rays from the mirror surface).

Dynamical system of the visual communication is the system, which changes the states under the action of external and internal processes. It reaches the effective communication this way. The base of the modeling and predicting of the condition and behavior of the design system in time and space is the using different kinds of the dynamic in the visual communications. If we learn how to design its interactions, then the necessity in the infinitely reorganization of the system in the conditions of the constantly changeable environment will disappear. 


\section{References:}

1. Aakhus, M. (2007). Communication as Design. Communication Monographs, vol. 74, no. 1, March, 112-117. Retrieved from: https://doi.org/10.1080/ 03637750701196383

2. Frascara, J. (2004). Communication design : principles, methods, and practice. Allworth Press, New York, NY.

3. Kuznetsova, I.O., Sirak, V.V. (2015). Do pytannia pro vyznachennia terminu «rukh v dyzaini» [On the question of defining the term «movement in design»]. Zbior raportow naukowych. "Najnowsze badanie naukowe. Teoria, praktyka» (30.03.2015 31.03.2015). Warszawa: Wydawca: Sp. z o.o. «Diamond trading tour», 57-61. (in Ukrainian)

4. Messaris, P. (2003). Visual Communication: Theory and Research. Journal of Communication, 53(3), 551-556. Retrieved from: https://doi.org/10.1111/j.14602466.2003.tb02608.x 